\title{
Systemic therapy for limited stage small cell lung carcinoma
}

\author{
Vanita Noronha, Anbarasan Sekhar, Vijay Maruti Patil, Nandini Menon, Amit Joshi, Akhil Kapoor, \\ Kumar Prabhash
}

Department of Medical Oncology, Tata Memorial Hospital, Parel, Mumbai; Homi Bhabha National Institute, Mumbai, India

Contributions: (I) Conception and design: V Noronha, A Sekhar; (II) Administrative support: None; (III) Provision of study materials or patients: None; (IV) Collection and assembly of data: V Noronha, A Sekhar; (V) Data analysis and interpretation: V Noronha, A Sekhar; (VI) Manuscript writing: All authors; (VII) Final approval of manuscript: All authors.

Correspondence to: Kumar Prabhash. Professor, Department of Medical Oncology, Tata Memorial Hospital, Parel, Mumbai, India; Homi Bhabha National Institute, Mumbai, India. Email: kumarprabhashtmh@gmail.com.

\begin{abstract}
Systemic treatment in small cell lung carcinoma has been a challenge for oncologists for decades. The high propensity for recurrence is usually due to distant metastasis, which makes systemic treatment an essential component of treatment in small cell lung carcinoma. The regimen of cisplatin and etoposide (established in the mid-1980's) concurrently with thoracic radiotherapy followed by prophylactic cranial irradiation (PCI) remains the standard of care in limited stage disease. Despite numerous trials, this regimen has not been improved upon. The standard combination regimen of cisplatin and etoposide has been compared to alternative platinum-containing regimens with drugs like epirubicin, irinotecan, paclitaxel, topotecan, pemetrexed, amrubicin and belotecan. Non-platinum containing regimens like ifosfamide and etoposide have also been tested. Attempts to intensify therapy have included the addition of a third drug like paclitaxel, ifosfamide, tirapazamine, tamoxifen, and thalidomide. Maintenance therapy following induction with chemotherapy, vandetanib and interferon-alpha have also been attempted. Molecularly directed targeted therapies and immunotherapeutic agents are areas of active research. In this review, we discuss the various systemic therapy options in limited stage small cell lung carcinoma, from the historical regimens to the modernday therapy and promising areas of research. We also discuss the role of growth factors, the optimal number of chemotherapy cycles, the use of prognostic and predictive factors, the optimal timing of chemotherapy and the treatment of special populations of patients including older patients, and patients with comorbidities.
\end{abstract}

Keywords: Small cell lung cancer (SCLC); limited-stage; chemotherapy; immune therapy; targeted therapy; radiation; prophylactic cranial irradiation; etoposide; platinum

Submitted May 28, 2020. Accepted for publication Jun 29, 2020.

doi: $10.21037 /$ jtd-2019-sclc-11

View this article at: http://dx.doi.org/10.21037/jtd-2019-sclc-11

\section{Introduction}

Small cell lung cancer (SCLC) is an aggressive disease with a rapid doubling time. SCLC accounts for less than $15 \%$ of all lung cancers and unlike other types of lung cancer, it spreads early and usually presents with disseminated disease. The median overall survival (OS) in patients with disseminated disease ranges from 7-12 months; recently, survival has been prolonged by a median of $2-3$ months with the introduction of immune checkpoint inhibitors in the first-line setting. The 5 -year OS is approximately $6.4 \%(1,2)$.
Over 60 years ago, the Veterans Affairs Lung Group (VALG) provided a simple and practical staging system for SCLC, which in spite of the more recent recommendation of the International Association for the Study of Lung Cancer (IASLC) to stage SCLC according to the American Joint Committee on Cancer (AJCC) tumor-node-metastasis (TNM) staging system, is still widely followed today. As per the conventional VALG staging, limited stage (LS) SCLC is disease that is limited to one hemithorax and can be encompassed safely within a single radiation portal (3). Using the TNM staging system, LS SCLC refers to any 
T (except a tumor with multiple ipsilateral lung nodules that cannot be included in a single radiation portal), any $\mathrm{N}$, but no M., i.e., patients with no distant metastases (4). Approximately $40 \%$ of patients with SCLC present with LS disease (5).

SCLC is highly chemosensitive, with responses to chemotherapy often ranging between $60 \%$ and $80 \%$ (1). Unfortunately, these tumors are quick to recur and metastasize to regional or distant sites and if left untreated, the expected survival is just 2 to 4 months for recurrent or metastatic disease. The doubling time of this tumor is 86 days (range, 25-217 days) (6) and hence the National Institute for Health and Care Excellence (NICE) guidelines recommend that patients with SCLC should be evaluated by a thoracic oncologist within one week after the decision to offer therapy (7).

Contrasting to the tremendous progress that has been made in the therapy of non-small cell lung cancer (NSCLC) and to a lesser degree in extensive stage (ES) SCLC, for the past two decades, there has been very little change in the way we treat LS SCLC, i.e., the combination of platinum and etoposide (EP) with concurrent thoracic radiation therapy (TRT) still remains the most widely used regimen with clinical trials consistently reporting a median OS of 25 to 30 months and a 5 -year survival rate of $30 \%$ to $35 \%$ (8).

In this article, we comprehensively review the systemic therapy options available to treat LS SCLC ranging from the age-old concurrent chemoradiotherapy (CRT) to the latest ongoing immunotherapy trials.

\section{Materials and methods}

We searched PubMed using the terms "chemotherapy in small cell lung carcinoma", "treatment in limited stage small cell lung carcinoma", "newer agents in small cell lung carcinoma", "recent advances in treatment of limited stage small cell lung carcinoma", "management of poor performance status lung carcinoma", and "targeted therapies in small cell lung carcinoma". We excluded articles that were about NSCLC and selected those related to SCLC. We then selected the articles that were related to the management and systemic therapy of SCLC. We excluded articles for which the full text was not available, and articles that were not in English. We then searched in Google for details of ongoing trials and the abstracts of scientific meetings, and we also manually looked through the references of the selected articles.

\section{Historical regimens}

The journey of systemic therapy in SCLC, as with all solid tumors began with the introduction of nitrogen mustard in the 1940s. One of the earliest studies to evaluate the role of various therapies in lung cancer was by the Veterans Administration Cooperative Study of the Therapy of Lung Cancer (9). They divided 496 patients with lung cancer (81 patients had SCLC) into groups that were treated with nitrogen mustard, steroid hormones (cortisone, diethyl stilbestrol, progesterone, testosterone) and an inert substance (lactose). The proportion of patients who were alive at the end of 90 days in the nitrogen mustard arm was $63 \%$, versus $51 \%$ in the inert substance arm and $37 \%$ in the cortisone-treated arm. The corresponding median OS were 121, 93 and 56 days respectively.

In 1969, the VALG reported their experience on the use of alkylating agents in patients with lung cancer. They found that nitrogen mustard led to better responses in patients with squamous cell lung cancer while cyclophosphamide was the preferred agent in patients with small cell undifferentiated carcinoma (10). This was the first study that demonstrated a statistically significant survival advantage from cyclophosphamide versus placebo (4 versus 1.5 months).

Subsequently, various other chemotherapeutic agents have been found to have single agent activity in SCLC. These include epipodophyllotoxins like etoposide, platinum compounds, anthracyclines, paclitaxel, docetaxel, gemcitabine, amrubicin, vinorelbine and temozolomide. These have been tested mainly in patients with relapsed/ refractory SCLC and have demonstrated modest efficacy (11). One of the major breakthroughs in the treatment of SCLC was the realization that combining multiple noncross resistant chemotherapy agents led to better results than single agents alone. In 1973, Livingston et al. studied the kinetically scheduled combination of vincristine and bleomycin in 15 patients with lung cancer, one of whom had SCLC. This combination was chosen based on the low myelosuppressive potential of bleomycin. The ORR to this regimen was $27 \%$ (12). In the subsequent year, Einhorn and colleagues studied the four-drug combination of bleomycin, doxorubicin, cyclophosphamide and vincristine in 29 patients with SCLC; 4 had LS SCLC. All the patients with LS SCLC attained a complete remission (CR), and in 2 patients, the responses were durable; sustained at 52 and 60 weeks. The median OS from the initiation of therapy 
was 35 weeks. The major toxicity was leucopenia; $10 \%$ patients developed neutropenic infection and there was 1 (3.4\%) drug-related death (13).

Despite being a highly chemosensitive tumor, even the combination of multiple agents led to only a short OS as almost all patients relapsed. Relapse in the intrathoracic region occurred in $75-90 \%$ of patients treated with chemotherapy alone for LS SCLC (14). Addition of TRT to the first line therapy increased the toxicity, but led to increased remissions, lower risk of local failures and prolonged survival $(15,16)$. Concurrent CRT has now become the current established standard of care for LS SCLC.

\section{Two drug combination regimens}

\section{Etoposide with cisplatin (EP) combination}

From studies in mice, it was noted that the addition of cisplatin to etoposide led to synergistic effects (17). In 1979, Sierocki et al. reported that an induction regimen of EP alternating with cyclophosphamide, doxorubicin and vincristine (CAV) led to ORR of $100 \%$ in LS SCLC [52\% CR and 48\% partial remission (PR)]. The tumors responded rapidly, and responses peaked by 6 weeks. Side-effects included myelosuppression, renal failure, nausea, vomiting and alopecia (18). Subsequently, Evans et al. used EP alone as induction therapy in 31 patients with SCLC, 11 of whom had LS SCLC. The ORR was $86 \%$ ( $43 \% \mathrm{CR}$ and $43 \% \mathrm{PR}$ ). The median duration of response in patients with LS SCLC was 39 weeks, and the median OS in responding LS SCLC patients was 70 weeks (19). Subsequently, EP with concurrent TRT has become the standard of care for LS SCLC.

EP has been evaluated concurrently along with altered fractionation schedules. Altered fractionation could include accelerated regimens, in which the same total dose is delivered in a shorter period, or hyperfractionated regimens in which two or more fractions of a lower dose are delivered in a day. In the pivotal Intergroup 0096 study, 417 patients with LS SCLC were randomly assigned to EP with concurrent 45 Gy of TRT, either delivered once daily over 5 weeks or twice daily over 3 weeks. Grade 3 esophagitis was more common at $27 \%$ in the twice-daily radiation arm compared to $11 \%$ in the once-daily arm. The median OS, 2-year OS and 5 -year OS were significantly better in the twice-daily compared to the once-daily TRT arms at 23 vs. 19 months, $47 \%$ vs. $41 \%$, and $26 \%$ vs. $16 \%$ respectively; $\mathrm{P}=0.04$ (20). However, critics of the study noted that the patients in the standard arm received a suboptimal TRT dose of 45 Gy.
The CONVERT trial (8) was a superiority trial that sought to answer this question; the standard arm was EP with twice-daily TRT based on the Intergroup 0096 study. 547 patients with LS SCLC were randomized to EP for 4 to 6 cycles, concurrent with TRT (starting on day 22 of EP chemo) as either 66 Gy in 33 fractions of 2 Gy each, once daily over 45 days or 45 Gy in 30 fractions of 1.5 Gy each, twice a day over 19 days. Toxicities were similar between the two arms other than a higher incidence of grade 4 neutropenia in the twice-daily TRT arm (49\% vs. 38\%, $\mathrm{P}=0.05)$. There was no difference in efficacy endpoints between the two arms: median OS and 2-year OS in the twice-daily TRT vs. once-daily TRT arms were $30 v s$. 25 months (HR, 1.18; 95\% CI, 0.95 to $1.45 ; \mathrm{P}=0.14$ ), and $56 \%$ vs. $51 \%$ respectively. Since this was not a noninferiority trial, the authors concluded that EP with twicedaily TRT should remain the standard of care. However, due to logistic challenges, inconvenience to patients, concerns regarding toxicity and the fact that there was no apparent survival benefit in the twice-daily TRT arm, the most commonly used regimen for LS SCLC continues to be EP with once-daily TRT with standard fractionation: 60 to $66 \mathrm{~Gy}$ in 30 to 33 fractions $(21,22)$. The Alliance for Clinical Trials in Oncology is conducting NCT00632853, a Phase III trial comparing once daily radiation (70 Gy in 2 Gy/fraction daily for 7 weeks) or twice daily radiation (45 Gy in 1.5 Gy/fraction twice a day for 3 weeks), combined in both arms with 4 cycles of EP (23).

\section{Epirubicin-based combination regimen}

In 2004, the Spanish Lung Cancer group reported a multicenter randomized controlled trial (RCT) that compared high dose epirubicin (Ep, $100 \mathrm{mg} / \mathrm{m}^{2}$ on day 1 every 21 days) and cisplatin (P, $100 \mathrm{mg} / \mathrm{m}^{2}$ on day 1 every 21 days) to the standard EP regimen (E, $100 \mathrm{mg} / \mathrm{m}^{2}$ on days 1 to 3 with $\mathrm{P}, 100 \mathrm{mg} / \mathrm{m}^{2}$ on day 1 every 21 days) for 6 cycles in newly diagnosed SCLC patients (24). Of the 402 patients included in the study, 207 (51.5\%) had LS SCLC; these patients received TRT; prophylactic cranial irradiation (PCI) was administered to those who attained a CR. The ORRs were similar between the two arms (EP-68.7\% vs. EpP$74.5 \%$ ) and there was no difference in OS, which was the primary endpoint (EP-10.1 months vs. EpP-10.4 months). Patients with LS SCLC had a better ORR (EP, 78.5\%; EpP, $82.0 \%)$ and a better median OS (12.9 months in both the arms). Patients in the EpP arm experienced less toxicity, and the difference was significant in patients with LS SCLC (54.7\% vs. $37 \%$; $\mathrm{P}=0.005)$ (24). Thus, $\mathrm{EpP}$ is a valid 
treatment option for LS SCLC.

\section{Irinotecan-based combination regimens}

Han and colleagues at the National Cancer Center in Korea studied the role of irinotecan with cisplatin as induction therapy in a phase II trial in LS SCLC (25). They treated 35 patients with 2 cycles of induction irinotecan (I, $80 \mathrm{mg} / \mathrm{m}^{2}$ ) and cisplatin $\left(\mathrm{P}, 40 \mathrm{mg} / \mathrm{m}^{2}\right)$ on days 1 and 8 every 21 days, followed by EP and concurrent twice-a-day TRT. The ORR to induction IP was $97 \%$ (9\% CR, 89\% PR), which increased to $100 \%$ after EP CRT. The median PFS was 12.9 months, the median OS was 25 months (95\% CI, 19 to 30.9 ), the 1 -year OS was $85.7 \%$ and the 2 -year OS was $53.9 \%$. Grade 3 and higher neutropenia and febrile neutropenia occurred in $68 \%$ and $20 \%$ of patients respectively during induction IP, and in $100 \%$ and $60 \%$ respectively during EP CRT.

A similar phase II study, the CALGB 30206 in 75 patients with LS SCLC evaluated the role of induction IP consisting of irinotecan, $65 \mathrm{mg} / \mathrm{m}^{2}$ and cisplatin $30 \mathrm{mg} / \mathrm{m}^{2}$ on days 1 and 8 every 3 weeks for 2 cycles followed by etoposide and carboplatin concurrently with TRT (26). The ORR was $71 \%$ (7\% CR and $64 \% \mathrm{PR}$ ), which increased to $88 \%$ as the best response to all therapy. The median PFS, median OS, 1-year OS and 2-year OS were 12.6 months, 18.1 months, $69 \%$ and $31 \%$ (95\% CI, 22-43\%). The preplanned target for 2-year OS of $60 \%$ was unfortunately not met.

A phase I dose escalation study found that irinotecan at $60 \mathrm{mg} / \mathrm{m}^{2}$ on days $1,8,15$ with cisplatin $20 \mathrm{mg} / \mathrm{m}^{2}$ on days 1 to 3 and 29 to 31 (IP) concurrently with conventional fractionated TRT, followed by 4 cycles of consolidation chemotherapy was well tolerated with no dose limiting toxicity (27). However, IP administered as a once-in-3-weeks regimen with concurrent TRT was excessively toxic (28). Three phase II studies have evaluated the efficacy and toxicity of IP concurrently with radiotherapy (29-31). The doses of irinotecan in two of the three trials was $60 \mathrm{mg} / \mathrm{m}^{2}$ on days 1, 8 and 15 every 4 weeks. The ORR ranged from $85 \%$ to $93 \%$ and the median OS ranged from 20 to 26 months. The common toxicities were gastrointestinal (diarrhea in 20\% to $35 \%)$, asthenia (67\%), pneumonitis (18\%), esophagitis (56\%) and neutropenia $(60 \%$ to $80 \%)$. There have not been any phase III studies evaluating this regimen in LS SCLC.

The question of the role of consolidation IP after EPbased induction CRT in LS SCLC was answered by the JCOG 0202, which was a phase III multicentric RCT in 281 Japanese patients with untreated LS SCLC (32). All patients received one cycle of EP $\left(\mathrm{E}-100 \mathrm{mg} / \mathrm{m}^{2}\right.$ days 1 to
3; P-80 $\mathrm{mg} / \mathrm{m}^{2}$ on day 1$)$ with accelerated hyperfractionated TRT (1.5 Gy twice a day, 5 days a week for 3 weeks, total 45 Gy). Patients who did not develop progressive disease $(\mathrm{PD})$ were randomized to three cycles of EP or IP (I-60 mg/ $\mathrm{m}^{2}$ on days $1,8,15$ and P-60 $\mathrm{mg} / \mathrm{m}^{2}$ on day 1 ). PCI was administered to patients who attained a CR or near-CR. There was no difference in the median OS, which was the primary endpoint of the study; EP-3.2 years versus IP-2.8 years; hazard ratio (HR), 1.07; 95\% CI, 0.8-1.46; $\mathrm{P}=0.7$. The 3 -year OS in the EP and IP groups were $52.9 \%$ and $46.6 \%$ and the 5 -year OS were $35.8 \%$ and $33.7 \%$ respectively. During the consolidation chemotherapy phase, the grade 3 and higher toxicities in the EP versus IP arms were neutropenia ( $95 \%$ vs. $78 \%$ ), anemia ( $35 \%$ vs. $39 \%)$, thrombocytopenia ( $21 \%$ vs. $5 \%)$, febrile neutropenia (17\% vs. $14 \%)$ and diarrhea ( $2 \%$ vs. $10 \%)$. Thus, this was a negative trial and EP CRT retained its position as the treatment of choice in LS SCLC.

\section{Other platinum-based regimens}

Several other trials have evaluated the role of other two drug platinum-based combination regimens, like paclitaxel + carboplatin (33), topotecan + cisplatin (34), pemetrexed + carboplatin (35), amrubicin + cisplatin (36) and belotecan + cisplatin (37). All these trials have been done in patients with ES SCLC, and there are no data to support the use of these regimens in LS SCLC.

\section{Non-platinum containing regimen}

In 1987, Wolf et al. reported on a novel non-platinumbased combination regimen, ifosfamide and etoposide (IE), which was compared to the EP regimen in 144 patients with untreated SCLC, both LS and ES. Patients received 6 cycles of either IE or PE at an interval of 3 weeks, followed by TRT (45 Gy) in patients with LS SCLC and PCI in patients who attained a CR. ORRs were similar (IE, 68\% vs. EP, 65\%), but CR rates in LS SCLC were higher in the EP arm (50\%) compared to IE (24\%). The median OS in patients with LS SCLC was 14.8 months in the EP arm and 11 months in the IE arm; the 2-year OS was also higher in the EP arm at $23 \%$ vs. $10 \%$ in IE arm. The study team concluded that EP was superior to IE in patients with LS SCLC (38).

\section{Addition of a third drug}

\section{Cyclophosphamide-epirubicin-vincristine (CEV) regimen}

The Norwegian Lung Cancer Study Group conducted 
a phase III RCT to compare EP with the CEV regimen in 436 patients with SCLC, 214 (49\%) of whom had LS SCLC. The regimens evaluated consisted of 5 cycles of EP (etoposide $100 \mathrm{mg} / \mathrm{m}^{2} \mathrm{IV}$ on day 1 , followed by oral etoposide $200 \mathrm{mg} / \mathrm{m}^{2}$ on days 2 to 4 , and cisplatin $75 \mathrm{mg} / \mathrm{m}^{2}$ $\mathrm{IV}$ on day 1) compared to 5 cycles of $\mathrm{CEV}$ (epirubicin $50 \mathrm{mg} / \mathrm{m}^{2}$, cyclophosphamide $1000 \mathrm{mg} / \mathrm{m}^{2}$ and vincristine $2 \mathrm{mg}$ all drugs administered IV on day 1). The patients with LS SCLC received TRT starting from cycle 3, and all patients who achieved a CR received PCI. The median OS in the LS SCLC was significantly longer in the EP arm at 14.5 months compared to the $\mathrm{CEV}$ arm at 9.7 months, $\mathrm{P}=0.001$. The 2 -year and 5-year OS were also significantly longer in the EP arm (25\% and $10 \%$ respectively) compared to the CEV arm (8\% and $3 \%$ respectively), $\mathrm{P}=0.0001$. Quality of life (QOL) was similar in the two arms. EP CRT continued to remain the treatment of choice for LS SCLC (39).

\section{Ifosfamide-based three drug combination regimen}

Glisson et al. (40) reported that in a phase II trial in 67 patients with LS SCLC, ifosfamide, cisplatin and oral etoposide with accelerated hyperfractionated TRT resulted in a response rate of $78 \%(67 \% \mathrm{CR})$, median PFS of 12.7 months, median OS of 23.7 months, and $2-$ and 3 -year OS rates of $50 \%$ and $39 \%$ respectively. Adverse events included grade 4 neutropenia in $55 \%$, grade 4 thrombocytopenia in $26 \%$, febrile neutropenia in $10 \%$ and grade 3 and higher esophagitis in $43 \%$. The Hoosier Oncology Group also conducted a phase II trial to evaluate the combination of ifosfamide (with mesna), etoposide and cisplatin with TRT in 53 patients with LS SCLC (41). The response rate was $68 \%$ ( $47 \%$ CR), median OS was 15.1 months, 1-, 2- and 5-year OS rates were $69.8 \%$, $35.9 \%$, and $13.2 \%$, respectively. Major grade 3 and higher toxicities included neutropenia in $75 \%$, anemia in $38 \%$ and thrombocytopenia in 34\%. Fatal toxicities occurred in $7.5 \%$ patients. In a phase III study in 171 patients with ES SCLC, the combination of ifosfamide with EP led to superior TTP and OS as compared to EP (42); however, there is no level 1 evidence for its role in LS SCLC.

\section{Taxane-based three drug combination regimens}

The Phase II Dutch multicenter trial (43) of paclitaxel, etoposide and carboplatin with TRT and PCI in 38 patients with LS SCLC and the phase II RTOG 9609 trial (44) of paclitaxel, etoposide and cisplatin with accelerated hyperfractionated TRT and PCI in 53 patients with LS SCLC led to promising outcomes. In the Dutch trial, the response rate was $92 \%$, median OS was 19.5 months, 1-, 2and 5 -year OS rates were $70 \%, 47 \%$ and $27 \%$ respectively. Hematological toxicities of grade 3 or higher occurred in $57 \%$ patients, febrile neutropenia in $24 \%$, esophagitis in $27 \%$ with no fatal toxicities. In RTOG 9609 (44), the response rate was $92 \%$, median OS was 24.7 months, 2-year OS was $54.7 \%$; grade 3 and higher toxicities included neutropenia in $75 \%$, esophagitis in $36 \%$, infection in $2 \%$ and fatal toxicities in $6 \%$. Hematological toxicities were significant, and the three-drug regimen did not improve on the OS historically reported from the Intergroup study and earlier studies of EP CRT. Therefore, this regimen was not pursued further.

The Greek Lung Cancer Cooperative Group conducted a multicenter randomized study in 133 patients with SCLC [89 (67\%) had LS SCLC] to evaluate the addition of paclitaxel to EP (TEP). In the patients with LS SCLC, TRT (50 Gy in 25 fractions) was started after the completion of chemotherapy, and patients who attained a CR were advised PCI. The ORR, time to progression, median OS and 1-year OS in the patients with LS SCLC in the TEP versus EP arms were $55 \%$ vs. $70 \%, 12$ vs. 10 months, 14 vs. 12.5 months and $58.6 \%$ vs. $55 \%$ respectively. This trial was prematurely closed due to significantly higher toxicity and mortality in the TEP arm (13\% in TEP arm vs. 0 in EP at the early interim analysis) without a commensurate improvement in efficacy outcomes compared to EP alone (45).

\section{Other drugs added to EP CRT}

Tirapazamine is a benzotriazine di-N-oxide that selectively targets and kills hypoxic cells, and thus could enhance the cytotoxic effects of radiation. A pilot study, S0004, evaluating the addition of tirapazamine to EP and oncedaily TRT in LS SCLC reported a median OS of 22 months (46). The phase II study, SWOG 0222 (47), was unfortunately prematurely closed (72 of 85 planned patients were accrued) when a parallelly running study of tirapazamine in patients with head and neck cancer reported excessive toxicity. In the SWOG 0222 study, $46 \%$ patients experienced grade 4 toxicities, predominantly hematologic. The ORR was $63 \%$, median PFS was 11 months and the median OS was 21 months. Although tirapazamine was not studied further, the concept of hypoxia-targeted agents in SCLC is attractive.

Based on the preclinical and clinical evidence that tamoxifen enhanced the efficacy of cisplatin-based regimens, the CALGB 9235 conducted a phase III trial comparing 
high dose tamoxifen ( $80 \mathrm{mg}$ orally twice a day for 5 days, starting on day 1 of cisplatin) with standard EP CRT versus EP CRT alone in 307 patients with LS SCLC (48). There was no difference in ORR, failure free survival, OS or toxicities between the two arms.

Lee $e t$ al. conducted a phase III RCT in 724 patients with SCLC (51\% had LS SCLC) evaluating whether the addition of thalidomide to EP improved outcomes (49). The 368 patients with LS SCLC received etoposide and carboplatin for 6 cycles, followed by TRT and PCI in patients who attained a CR or PR. Patients were randomized to receive thalidomide daily for 2 years or placebo. There was no difference in OS between the two arms in the patients with LS SCLC; median OS in the thalidomide and placebo arms was 12.1 and 13.1 months respectively; HR, 0.91; $95 \%$ CI, 0.73 to 1.15 . Thalidomide doubled the risk of thromboembolism and led to more constipation, rash, and neuropathy.

Thus, in spite of numerous trials evaluating newer and more modern regimens for LS SCLC, EP with concurrent TRT remained the standard of care.

\section{Sequencing of chemotherapy with radiotherapy}

The meta-analyses by Pignon et al. (16) and Warde et al. (50) established that concurrent CRT improved survival and local control over chemotherapy alone in LS SCLC. Pignon et al. reported that the addition of TRT to chemotherapy led to a $14 \%$ reduction in the risk of death, while Warde et al. found that there was a $5.4 \%$ absolute improvement in the 2-year survival and a doubling of the local control rate from $25 \%$ with chemotherapy alone to $50 \%$ after the addition of TRT. The sequencing of chemotherapy with TRT has been extensively studied. The Japan Clinical Oncology Group 9104 study evaluated the optimal timing of TRT with EP chemotherapy. The study enrolled 231 patients with LS SCLC; all patients received 4 cycles of EP and TRT consisting of 45 Gy as 1.5 Gy fractions twice a day over 3 weeks. Patients were randomized to start TRT either on the second day of cycle 1 of chemotherapy (concurrent arm) or after all 4 cycles (sequential). Patients treated with sequential therapy had a median OS of 19.7 months, which improved to 27.2 months in the concurrent arm. The $2-y r$ and 5 -yr OS in the sequential and concurrent arms were $35.1 \%$ vs. $54.4 \%$, and $18.3 \%$ vs. $23.7 \%$ respectively. Patients treated with concurrent CRT developed more hematological toxicities (51). Several trials and metaanalyses have subsequently confirmed that early initiation of chemotherapy with TRT results in a survival benefit (52-54).

The CALGB 30904 was a pooled analysis of 200 patients from three studies (CALGB 39808, CALGB 30002 and CALGB 30206) that tested the strategy of induction chemotherapy (2 cycles; regimens included topotecan + paclitaxel, etoposide + paclitaxel + topotecan, and cisplatin + irinotecan), followed by concurrent CRT with EP (etoposide + carboplatin) and TRT started on day 43 to a dose of 70 Gy, delivered in once daily 2 Gy fractions. Patients who attained a CR or a very good PR were offered PCI. The pooled ORR from induction chemotherapy was $72 \%$, which increased to $88 \%$ post-CRT. Common grade 3 and higher toxicities from induction chemotherapy were neutropenia in $30 \%$ of patients, and diarrhea in $10 \%$. During CRT, the common grade 3 and higher toxicities included neutropenia in $80 \%$, leukopenia in $48 \%$, thrombocytopenia in $43 \%$, anemia in $25 \%$, febrile neutropenia in $19 \%$, esophagitis in $23 \%$ and dehydration in $15 \%$. The locoregional control was $77 \%$, the pooled median OS was 19.9 months (95\% CI, 16.7 to 22.3), the median PFS was 12.3 months, the 2-year and 5 -year OS rates were $37 \%$ and $21 \%$ respectively (55).

An alternating schedule is one in which radiotherapy is delivered on the days that the patient does not receive chemotherapy. The ECOG conducted a pilot study in 34 patients with LS SCLC to evaluate the alternating schedule (56). Patients received EP every 3 weeks for 4 cycles, with TRT as 45 Gy in 1.5 Gy twice daily fractions given for 5 consecutive days after cycles 1, 2 and 3 of chemotherapy. Patients who attained a CR received one additional cycle of consolidation (LI, or late intensification) chemotherapy with cyclophosphamide $\left(4 \mathrm{~g} / \mathrm{m}^{2}\right)$ and etoposide $\left(900 \mathrm{mg} / \mathrm{m}^{2}\right)$. The decision for PCI was optional. The ORR was $97 \%$ (59\% CR and 38\% PR), median OS was 18 months. Toxicity was as reported from earlier trials, however the LI chemotherapy led to grade 4 neutropenia in all patients, 1 episode of adult respiratory distress syndrome and 2 deaths from sepsis. The investigators concluded that an alternating strategy led to similar outcomes and toxicity as standard concurrent CRT.

The "Petites Cellules" group conducted a trial in 164 patients who were randomized to concurrent CRT in which the radiation (50 Gy in 25 fractions) was started after cycle 2 of chemotherapy on days 30 to 64 versus an alternating schedule in which the radiation was delivered in three courses: 20 Gy in 8 fractions from days 36 to 47 (between cycles 2 and 3), days 64 to 75 (between cycles 3 and 4) and 15 Gy in 6 fractions from days 92 to 101 (between cycles 4 and 5) (57). Chemotherapy consisted of cyclophosphamide 
+ doxorubicin or vindesine + etoposide every 4 weeks. There was no significant difference in survival in the two arms (median OS of 13.5 and 14 months in the concurrent vs. alternating arms respectively, $\mathrm{P}=0.15$ ), with higher toxicity in the concurrent arm (6 patients $v s .1$ patient in the alternating arm, $\mathrm{P}=0.05)$.

Following EP CRT, the JCOG1011 evaluated whether dose-intensive weekly chemotherapy (cisplatin, doxorubicin, etoposide, vincristine; CODE) or amrubicin + cisplatin (AP) could result in an improvement in the 1-year PFS (58). The 1 -year PFS was $41 \%$ in the CODE arm vs. $54.3 \%$ in the AP arm; neither regimen led to the expected 55\% 1-year PFS, and were therefore not felt to be appropriate to take forward for a phase III study.

Despite the unequivocal benefit of concurrent CRT in LS SCLC, in the real world setting only $55 \%$ of patients receive both chemotherapy and TRT as the initial treatment. $20.5 \%$ receive chemotherapy alone, $3.5 \%$ receive radiation alone and $20 \%$ receive neither. The major barrier to receiving optimal therapy is financial, and lack of insurance coverage (59).

\section{Optimal number of chemotherapy cycles}

The standard of care for a patient with LS SCLC consists of 4 to 6 cycles of chemotherapy concurrently with TRT. In the Intergroup trial, all patients received 4 cycles of EP (20), while in the CONVERT trial, patients could receive 4 to 6 cycles of EP (8). The decision regarding 4 or 6 cycles in the CONVERT study was left to the enrolling center. $32 \%$ of the patients in the CONVERT trial were planned for 6 cycles; approximately $20 \%$ received 6 cycles. In a recent retrospective study from UK, 188 out of 671 patients had LS SCLC. Of these, 176 patients received 4 cycles and only 12 (6\%) received more than 4 cycles (60). Veslemes et al. randomized 70 patients with SCLC (both LS and ES) to receive 4 or 6 cycles of EP chemotherapy (61). There was no survival difference between the two arms in the patients with LS SCLC; median OS was 10.5 months in the patients who received 4 cycles of EP versus 12 months in patients who received 6 cycles, $P=0.21$. Toxicity was also similar in the two arms.

\section{The role of growth factors in LS SCLC}

The use of myeloid growth factors concurrently with TRT for patients with LS SCLC is controversial. The SWOG conducted a trial reported by Bunn $e t$ al. in which
230 patients with LS SCLC were randomized to CRT (6 cycles) with or without granulocyte-macrophage colony stimulating factor (GM-CSF) on days 4 to 18 (62). The primary endpoint, hematologic toxicity was significantly higher in the GM-CSF arm, specifically the frequency and duration of grade 3 and higher thrombocytopenia (91\% vs. $18 \%, \mathrm{P}<0.001)$. Additionally, non-hematologic toxicities (pulmonary complications, duration of hospitalization, transfusions and intravenous antibiotic use) and number of toxic deaths (9 vs. $1, \mathrm{P}<0.01)$ were higher with GM-CSF. Patients on the GM-CSF arm had a numerically lower CR rate (36\% vs. 44\%; $\mathrm{P}=0.29)$, and lower median OS (14 vs. 17 months; $\mathrm{P}=0.15)$, although these differences did not attain statistical significance. The authors concluded that hematopoeitic growth factors should not be used in patients receiving concurrent EP CRT for LS SCLC.

Forty percent of patients in the CONVERT trial received granulocyte colony stimulating factor (G-CSF). Gomes et al. reported that the patients in the CONVERT trial who received G-CSF had twice the frequency of severe thrombocytopenia $(29.4 \%$ vs. $13 \%$; $\mathrm{P}<0.001)$ and anemia (20\%), but both these numbers were lower than what had been described earlier. Patients required more supportive care measures including transfusion of platelets and blood. There was no increase in pulmonary toxicity, and survival (both PFS and OS) was similar in the two groups. The authors concluded that the use of G-CSF was safe in patients with LS SCLC on concurrent EP CRT (63). G-CSF is probably safer than GM-CSF, and modern radiation techniques are more evolved, with less risk of pulmonary toxicity. However, the study by Gomes et al. has only been presented in abstract form so far. In the CONVERT trial, febrile neutropenia occurred in $24 \%$ of the patients in twice-daily radiation arm, and in $19 \%$ of patients in the once-daily radiation arm. The 2015 ASCO guidelines for the use of growth factors recommend primary G-CSF prophylaxis for regimens that have an expected risk of febrile neutropenia of $20 \%$ or higher, however, the guidelines recommend the avoidance of G-CSF in patients receiving concurrent CRT especially if it involves the mediastinum (64). Thus, the role of myeloid growth factors along with concurrent EP CRT for patients with LS SCLC is still unclear.

\section{The choice of platinum therapy}

Cisplatin is associated with several adverse events like nephrotoxicity, dyselectrolytemia, neurotoxicity, deafness 
and GI side effects. In cisplatin-ineligible patients, i.e., patients with renal dysfunction, hearing loss and poor performance status (PS), carboplatin is used.

The Hellenic Cooperative Oncology Group for Lung Cancer Trials conducted a phase III trial comparing carboplatin $\left(300 \mathrm{mg} / \mathrm{m}^{2}\right.$ on day 1$)$ to cisplatin $\left(50 \mathrm{mg} / \mathrm{m}^{2}\right.$ days $1-2)$, both in combination with etoposide $\left(100 \mathrm{mg} / \mathrm{m}^{2}\right.$ days 1-3) every 3 weeks for 6 cycles. In the 82 of the 143 patients $(57 \%)$ who had LS SCLC, TRT was started in the third chemotherapy cycle and PCI was also administered in patients who attained a CR. In the patients with LS SCLC, the ORR in the cisplatin $v s$. carboplatin arms were $76 \%$ (44\% CR) vs. $86 \%$ (37\% CR). The median OS for patients with LS SCLC was 14.1 months, with no significant difference between those who received carboplatin and cisplatin. However, toxicities were significantly lower in the carboplatin-treated patients, including leucopenia, thrombocytopenia, nausea/vomiting, neurotoxicity, neutropenic infection, and hypersensitivity. Patients who received carboplatin required less hospitalizations. The authors concluded that when combined with etoposide, carboplatin is equiefficacious (in terms of response and survival) but less toxic than cisplatin (65).

Rossi et al. conducted an individual patient data metaanalysis of 4 RCTs including 663 patients with SCLC in the first line setting; $32 \%$ of the patients had LS SCLC (66). All outcomes were similar between patients treated with cisplatin and carboplatin; ORRs, median PFS and median OS for cisplatin- versus carboplatin-treated patients were $67.1 \%$ and $66 \%(\mathrm{P}=0.83), 5.5$ and 5.3 months (HR, 1.10; $95 \% \mathrm{CI}, 0.94$ to $1.29 ; \mathrm{P}=0.25$ ), and 9.6 and 9.4 months (HR, 1.08 ; $95 \%$ CI, 0.92 to $1.27 ; \mathrm{P}=0.37$ ). There was no evidence of heterogeneity of the treatment effect based on the stage of the disease; the treatment: stage interaction for PFS was $\mathrm{P}=0.57$ and for the OS; $\mathrm{P}=0.17$. The toxicities caused were different: carboplatin led to more myelosuppression, while cisplatin caused more nausea and vomiting, nephrotoxicity and neurotoxicity (66). Thus, carboplatin appears to be an acceptable choice in patients with LS SCLC. However, it must be noted that the pivotal trials (Intergroup and CONVERT) $(8,20)$ that have established the chemotherapy regimens and the TRT schedule for LS SCLC have all used cisplatin-based regimens; while the ongoing NCT00632853 trial (23) comparing accelerated hyperfractionated radiation with standard radiation in combination with chemotherapy permits either cisplatin or carboplatin in combination with etoposide as the concurrent chemotherapy regimen. Several of the ongoing maintenance immunotherapy trials also permit carboplatin as the platinum agent concurrently with radiation (67-70). A retrospective analysis in 73 patients with SCLC [29 (40\%) with LS SCLC], found that patients with a high neutrophil to lymphocyte ratio (NLR $\geq 3.8$ ), had a significantly longer median PFS when treated with cisplatin-based EP as compared to carboplatin (4.6 vs. 2.6 months; $\mathrm{P}=0.021$ ), as well as median OS (cisplatin, 15.7 vs. carboplatin, 7.8 months; $\mathrm{P}=0.042$ ). This difference in PFS was present in the LS SCLC subgroup of patients with high NLR as well; cisplatin, 6.5 months $v$ s. carboplatin, 2.8 months; $\mathrm{P}=0.002$ (71). These results are intriguing and worthy of further evaluation.

\section{Prognostic and predictive factors in LS SCLC}

Clinical stage is one of the most powerful prognostic factors in patients with SCLC. Within the stage grouping of LS SCLC, patients with no mediastinal lymph node involvement have a better survival. Patients with Stage I and II disease have a better survival compared to those with Stage III disease (median OS with EP CRT, 50 vs. 25 months; HR, 0.6; 95\% CI, 0.44 to $0.83 ; \mathrm{P}=0.001$ ) (72). Superior vena cava obstruction does not portend a worse prognosis in LS SCLC (73). Kawahara and colleagues categorized 147 LS SCLC patients (enrolled in a randomized study comparing EP, CAV and alternating $\mathrm{EP}$ and $\mathrm{CAV}$ ) into two groups based on the PS and the serum LDH; the group with a normal LDH and PS of 0 or 1 had a median OS of 18.1 months, while the group with an abnormal LDH and PS 2 or 3 had a median OS of 9.9 months; $\mathrm{P}<0.0001$ (74). Xie et al. analyzed 383 patients with LS SCLC and reported that the platelet to lymphocyte ratio, age, smoking cessation, chest radiation, chemotherapy, surgery, and PCI were of prognostic significance (75). There is no level 1 evidence to support the role of PET-CT scan in staging of SCLC, and a posthoc analysis of the CONVERT trial revealed that there was no difference in survival between the patients who were staged with or without a PET scan (72). However, a PET-CT scan, if done, can provide valuable prognostic information. In patients with LS SCLC, at baseline, a higher fluorodeoxyglucose tumor uptake correlates with a worse prognosis (76). Following therapy for LS SCLC, metabolic parameters on a scan including the metabolic tumor volume, the total lesion glycolysis, and the glucosecorrected maximum standardized uptake value (glu-SUV ${ }_{\text {max }}$ ) significantly predicted survival (77). 
In a retrospective cohort of 284 patients with LS SCLC, $80 \%$ of whom were treated with concurrent CRT, quitting smoking at the time of or after the diagnosis of SCLC decreased the risk of death by $45 \%$ (HR, $0.55 ; 95 \%$ CI, 0.38-0.79). Starting TRT within 1 month of the start of chemotherapy had prognostic significance on the univariate analysis, however, it did not retain significance in the multivariate adjusted model, while younger age, concurrent CRT and the delivery of platinum-based chemotherapy significantly impacted survival (78).

Radiotherapy factors that affect prognosis include early initiation of TRT (within 9 weeks of the start of chemotherapy), the use of concurrent CRT, and a short time period between the start of chemotherapy and the end of TRT (SER). (79) Following therapy, platinum-sensitive disease status is strongly associated with longer OS (80). Ding et al. reported that in 107 patients with LS SCLC with no evidence of brain metastases on the baseline MRI, who were treated with concurrent EP CRT and no PCI, 46.7\% of the patients developed brain metastases, at a median time of 10.7 months (range, 4.8 to 31.1 months) (81). Factors associated with better OS were receipt of $\geq 4$ cycles of chemotherapy $v s .<4$ cycles $(\mathrm{P}=0.015), \mathrm{CR} v s$. $\mathrm{PR}$ to initial treatment $(\mathrm{P}=0.007)$ and early TRT, i.e., started during cycle 3 of chemotherapy $v$ s. late radiation $(\mathrm{P}=0.017)$. The factors that predicted a longer time to the development of brain metastases were a lower clinical stage (TNM Stage I or II vs. III, $\mathrm{P}=0.003)$, CR to initial therapy $(\mathrm{P}=0.031)$ and early TRT $(\mathrm{P}=0.097)$.

Approximately $60 \%$ of patients with LS SCLC have detectable circulating tumor cells (CTC) in the baseline blood sample, prior to initiation of concurrent EP CRT. The presence of CTCs correlates with a more aggressive clinical course and poorer outcomes. Patients with $<15$ CTC have a better prognosis as compared to those with $\geq 15$ CTC; median OS, 26.7 vs. 5.9 months ( $\mathrm{P}=0.001)$. In patients with $\geq 15$ CTCs at baseline, the median PFS was 5.5 months (vs. 19 months for $<15$ CTCs), $70 \%$ had a survival of $\leq 1$ year and $100 \%$ had a survival $\leq 2$ years (82).

Recently, a new molecular classification has been proposed for SCLC based on the differential expression of transcriptional regulators, achaete-scute homologue 1 (ASCL1 or ASH1), neurogenic differentiation factor 1 (NeuroD1), yes-associated protein 1 (YAP1) and POU class 2 homeobox 3 (POU2F3) (83). The role of these molecular subtypes, in terms of response to therapy, and impact on outcomes and survival are areas of active research.

\section{The role of adjuvant/maintenance/consolidation therapy in LS SCLC}

\section{Vandetanib}

Vandetanib is an oral tyrosine kinase inhibitor that targets VEGFR2. The BR .20 trial conducted by the National Cancer Institute of Canada Clinical Trials Group Study (NCIC) was a phase II RCT in 107 patients with SCLC [46 (43\%) had LS SCLC] evaluating the role of vandetanib as maintenance therapy in patients who had attained CR or PR following first line therapy (84). Patients on the vandetanib arm had higher incidence of diarrhea, hypertension, QTc prolongation and rash. Overall, this was a negative trial, with no survival advantage noted from vandetanib in PFS or OS. However, in patients with LS SCLC, a trend towards a better survival was noted; the median PFS in the vandetanib arm was 9.99 vs. 6.67 months in the placebo arm (HR, $0.8 ; 80 \% \mathrm{CI}, 0.5$ to 1.3 ) and the median OS in the placebo treated patients was 21.2 months versus not reached in the vandetanib arm; $\mathrm{HR}, 0.5$; $95 \% \mathrm{CI}, 0.2$ to 0.9 .

\section{Bec2/bacille Calmette-Guerin (BCG) vaccine}

The EORTC 08971-08971B Silva Study was a phase III study in 515 patients with LS SCLC who had received concurrent CRT and had a major response (85). Patients were randomized to 5 doses of Bec2/BCG vaccine or observation. The vaccine did not lead to an improvement in QOL, PFS or OS; median OS was 14.3 months in the vaccine arm compared to 16.4 months in the observation arm, $\mathrm{P}=0.28$.

\section{Interferons}

The SWOG study evaluated the role of maintenance recombinant interferon alpha-2a (3 million units $/ \mathrm{m}^{2}$ escalated to 9 million units $/ \mathrm{m}^{2}$ subcutaneously 3 times a week for 2 years) in 121 patients with LS SCLC who had an objective response to CRT (86). The median OS in the interferon arm was 13 vs. 16 months in the observation arm, $\mathrm{P}=0.77$. Grade 3 and higher toxicities included malaise, fatigue, leukopenia, neutropenia, dyspnea, nausea and respiratory infection. Sixty-seven percent patients discontinued therapy due to toxicities. Various other studies that evaluated whether interferons as maintenance therapy may play a role in improving outcomes in SCLC have also been disappointing $(87,88)$. 


\section{Maintenance therapy meta-analysis}

A meta-analysis by Rossi et al. evaluating 21 RCTs done in 3687 patients with SCLC (both LS SCLC and ES SCLC) showed that overall, there was no statistically significant benefit in terms of prolongation of PFS or OS from the maintenance or consolidation therapy approach (89). The meta-analysis included 11 RCT's that evaluated maintenance chemotherapy, 6 evaluated interferons and 4 evaluated other biological agents (matrix metalloprotease inhibitors, Bec2/ BCG vaccination, thalidomide, vandetanib). Maintenance chemotherapy led to a statistically significant prolongation in PFS and OS; however, in absolute terms, this did not appear to be clinically relevant as it translated to an improvement of 2 weeks in OS, and a $4 \%$ improvement in 1-year OS from $30 \%$ to $34 \%$. Interferon-alpha also led to a significant improvement in PFS and OS; in absolute terms, this was an improvement of 3.5 weeks in OS, and a $9 \%$ improvement in 1-year OS (from $30 \%$ to $39 \%$ ). The studies included in the meta-analysis were of low-quality, the data were heterogenous and the analysis was not based on individual patients' data.

\section{Novel therapeutic strategies}

\section{Bevacizumab}

Bevacizumab is well known angiogenesis inhibitor used in NSCLC, colon cancer, breast cancer and renal cancer. A phase II study in the Sarah Cannon Oncology Research Consortium evaluated the addition of bevacizumab to carboplatin and irinotecan concurrently with TRT and optional PCI, followed by maintenance bevacizumab for 6 months in patients who did not progress. The study was terminated early for safety concerns after 29 patients were enrolled. Two patients developed tracheoesophageal fistulae (one fatal) and one additional patient had fatal aerodigestive bleeding (90).

\section{Immunotherapy}

SCLC is strongly associated with smoking and has been shown to harbor a high load of non-synonymous somatic mutations (high tumor mutational burden), both of which features suggest that immunotherapy may be active in SCLC.

The ongoing Phase I NCT02402920 trial is evaluating the addition of pembrolizumab to concurrent CRT in patients with LS SCLC and ES SCLC (67). The combination of the programmed cell death protein 1 (PD-1) inhibitor, nivolumab and the anticytotoxic T-lymphocyteassociated antigen-4 (CTLA-4) inhibitor, ipilimumab, are being evaluated in the maintenance setting after completion of concurrent CRT (Phase II STIMULI trial, NCT02046733) (68). The Phase II/III NCT03811002 trial in 506 patients with LS SCLC is evaluating the addition of atezolizumab to EP CRT (atezolizumab on day 1 or 2 of each chemotherapy cycle), followed by atezolizumab administered every 3 weeks up to 1 year (69). The Phase III ADRIATIC study is a double blind placebo controlled multicenter global study evaluating the role of the anti PDL1, durvalumab with or without the CTLA4 inhibitor, tremelimumab as consolidation therapy in patients with LS SCLC who have non-progressive disease after concurrent CRT (70). Currently, there are no completed studies that support the role of immunotherapy in LS SCLC. However, immunotherapy has been shown to improve outcomes in extensive stage SCLC in the first line setting (OS improved by atezolizumab with platinum-etoposide in IMpower133 (2), OS improved by durvalumab with platinum-etoposide in the CASPIAN study (91), and PFS improved by pembrolizumab with platinum-etoposide in KEYNOTE-604) (92) as well as in locally advanced NSCLC after completion of CRT (PACIFIC study) (93).

\section{Special patient populations}

\section{Chemotherapy in older patients}

SCLC commonly occurs in older patients. The median age of patients enrolled in the CONVERT trial was 62 to 63 years; $15 \%$ of the patients were over the age of 70 years (8). In a retrospective analysis of two RCTs conducted by the NCIC in 608 patients with LS SCLC, all treated with CAV followed by EP, with TRT and PCI, Siu et al. reported that although patients aged 70 years and older received lower overall doses of drugs as compared to the planned doses, yet there was no significant difference in toxicity and increased age was not a poor prognostic factor (94).

Safont et al. reported the retrospective analysis of the RCT conducted by the Spanish Lung Cancer Group evaluating high dose EpP in 402 patients with SCLC (95). They found that older patients with LS SCLC received a lower total cisplatin dose (401 vs. $\left.508 \mathrm{mg} / \mathrm{m}^{2}, \mathrm{P}=0.01\right)$, but had fewer dose delays (10 vs. 15 days, $\mathrm{P}=0.05$ ). There was no difference in toxicities and a trend to lower TTP and OS in patients over 70 years old. 
From the National Cancer Data Base, Corso et al. identified 8,637 patients aged $\geq 70$ years with LS SCLC that had been treated with chemotherapy or concurrent CRT (96). They found that there were decreased odds of receiving concurrent CRT with increased age, clinical stage III disease (versus clinical stage I or II), female sex and increasing comorbidities. Concurrent CRT led to a survival benefit over chemotherapy alone; median OS, 15.6 vs. 9.3 months; 3 -year OS was $22 \%$ vs. $6.3 \%$; $\mathrm{P}<0.001$.

In the Intergroup 0096 trial, 15 out of 381 (13\%) patients were 70 years or over (20). As compared to patients below 70 years, older patients developed more severe hematologic toxicities (grade 4 and higher, $61 \%$ vs. $84 \%$; $\mathrm{P}<0.01$ ), similar non-hematologic toxicities and more fatal toxicities ( $1 \%$ vs. $10 \%, \mathrm{P}=0.01$ ). There were no differences in ORRs (88\% vs. $80 \% ; \mathrm{P}=0.11)$, 5 -year event free survival rates $(19 \%$ vs. $16 \%, \mathrm{P}=0.18$ ), but 5 -year OS rates were higher in the younger patient cohort ( $22 \%$ vs. $16 \%, \mathrm{P}=0.05)$ (97).

In the North Central Cancer Treatment Group study comparing $\mathrm{EP}$ with once daily $v s$. twice daily radiation in LS SCLC, older patients (age 70 years and older) had more weight loss and poorer PS at presentation, and experienced more grade 4 and higher pneumonitis ( $8 \%$ vs. $0, \mathrm{P}=0.008$ ), more fatal toxicities $(5.6 \%$ vs. $0.5 \%, \mathrm{P}=0.03)$, but similar 2 -yr OS (33\% vs. $48 \%)$ and 5 -year OS (17\% vs. $22 \%)$, $\mathrm{P}=0.14$ (98).

Most recently, in the CONVERT trial, 67 (out of 490 evaluable) patients were 70 years or older and the median age was 73 years (range, 70 to 82 years) (99). The chemotherapy compliance was similar between the younger and older cohort of patients, but only $73 \%$ of the older cohort received an optimal number of radiation fractions versus $85 \%$ of the younger cohort, $\mathrm{P}=0.03$. Grade 3 and higher neutropenia was higher in the older cohort $(84 \%$ vs. $70 \%, \mathrm{P}=0.02)$, but there was no difference in the rates of febrile neutropenia ( $4 \%$ vs. $7 \%, \mathrm{P}=0.07)$ or death $(3 \%$ vs. $1.4 \%, \mathrm{P}=0.67)$. There was also no significant difference in survivals; median TTP was 18 vs. 16 months (HR, 1.04; 95\% CI, 0.76 to $1.41 ; \mathrm{P}=0.81$ ) and median $\mathrm{OS}$ was 29 vs. 30 months (HR, 1.15; 95\% CI, 0.84 to 1.59 ; $\mathrm{P}=0.38$ ).

Thus, in the trial setting, although older patients overall had more toxicities from standard therapy, efficacy outcomes were similar to those of younger patients. Appropriate patient selection is important. In the realworld setting, often patients are not as fit as those enrolled on trials. Ludbrook et al. reported the outcomes of 174 patients with LS SCLC (100). They grouped patients into three age groups: $<65$ years $(n=55,32 \%), 65-74$ years
( $\mathrm{n}=76,44 \%)$, and $\geq 75$ years $(\mathrm{n}=43,25 \%)$; and according to the Charlson comorbidity index (CCI) scores 0,1 , and $\geq 2$. They found that older patients had worse PS and more comorbidities, were less likely to undergo diagnostic scans, less likely to receive concurrent CRT, more likely to receive less intensive chemotherapy regimens with fewer cycles and lower total doses, and less likely to receive PCI. Treatment related toxicities were similar, but response rates $(91 \%$ in $<65$ years, $79 \%$ in $65-74$ years and $74 \%$ in $\geq 75$ years; $\mathrm{P}=0.014)$, median OS $(17,12$, and 7 months) and 2-year survival $(37 \%, 22 \%$, and $19 \% ; \mathrm{P}=0.003)$ were significantly lower with increasing age. However, on multivariate analysis, good PS, normal LDH, absence of pleural effusion, and the receipt of 4 or more cycles of chemotherapy were independently associated with survival while age and the comorbidity index were not.

\section{Patients with comorbidities}

Halvorsen et al. evaluated the outcomes of 157 patients with LS SCLC with comorbidities enrolled in an RCT comparing EP with two schedules of TRT: 45 Gy/30 fractions twice a day or $42 \mathrm{~Gy} / 15$ fractions once a day. When evaluated using the CCI, $40 \%$ of the patients had no comorbidity, $34 \%$ had CCI-score 1, 15\% CCI 2; and $11 \%$ had CCI 3-5 (101). When evaluating patients based on the CCI score categories, there were no differences in the rates of completion of chemotherapy, TRT, or PCI; and no significant differences in the development of grade 3 and higher toxicity $(\mathrm{P}=0.49)$, fatal toxicities $(\mathrm{P}=0.36)$, response rates $(\mathrm{P}=0.20)$, $\mathrm{PFS}(\mathrm{P}=0.18)$ or $\mathrm{OS}(\mathrm{P}=0.09)$. Thus, the presence of comorbidities does not impact on tolerance to or outcomes of CRT in patients with LS SCLC. However, the drawback of this study is the small sample size, especially in the subgroup of patients with CCI score 3 to 5 (17 patients), making it hard to make definitive conclusions.

\section{Conclusions}

In spite of multiple trials attempting to improve the outcomes in patients with LS SCLC, the regimen of EP with TRT continues to remain the gold standard. High dose epirubicin and cisplatin may represent a valid option in combination with TRT. There is no established role for maintenance or consolidation therapy. Multiple mutations exist, but most of the newer drugs have not been found to be effective. Immunotherapy thus far does not have an established role is LS SCLC, but this is an area of active investigation. In older 
patients, EP CRT leads to more toxicities but comparable efficacy, and patient selection is key.

\section{Acknowledgments}

Funding: None.

\section{Footnote}

Provenance and Peer Review: This article was commissioned by the Guest Editor (Jose Pacheco) for the series "Small Cell Lung Cancer" published in Fournal of Thoracic Disease. The article was sent for external peer review organized by the Guest Editor and the editorial office.

Conflicts of Interest: All authors have completed the ICMJE uniform disclosure form (available at http:// dx.doi.org/10.21037/jtd-2019-sclc-11). The series "Small Cell Lung Cancer" was commissioned by the editorial office without any funding or sponsorship. Dr. Noronha reports grants from Dr. Reddy's Laboratories Inc., grants from Amgen, grants from Sanofi/Aventis, grants from AstraZeneca, outside the submitted work. Dr. Prabhash reports grants from Dr. Reddy's Laboratories Inc., grants from Fresenius Kabi India Pvt Ltd, grants from Alkem Laboratories, grants from Natco Pharma Ltd., grants from BDR Pharmaceuticals India Pvt. Ltd., grants from Roche Holding AG, outside the submitted work; The authors have no other conflicts of interest to declare.

Ethical Statement: The authors are accountable for all aspects of the work in ensuring that questions related to the accuracy or integrity of any part of the work are appropriately investigated and resolved.

Open Access Statement: This is an Open Access article distributed in accordance with the Creative Commons Attribution-NonCommercial-NoDerivs 4.0 International License (CC BY-NC-ND 4.0), which permits the noncommercial replication and distribution of the article with the strict proviso that no changes or edits are made and the original work is properly cited (including links to both the formal publication through the relevant DOI and the license). See: https://creativecommons.org/licenses/by-nc-nd/4.0/.

\section{References}

1. Wang S, Tang J, Sun T, et al. Survival changes in patients with small cell lung cancer and disparities between different sexes, socioeconomic statuses and ages. Sci Rep 2017;7:1339.

2. Horn L, Mansfield AS, Szczęsna A, et al. First-Line Atezolizumab plus Chemotherapy in Extensive-Stage Small-Cell Lung Cancer. N Engl J Med 2018;379:2220-9.

3. Micke P, Faldum A, Metz T, et al. Staging small cell lung cancer: Veterans Administration Lung Study Group versus International Association for the Study of Lung Cancer-what limits limited disease? Lung Cancer 2002;37:271-6.

4. Available online: https://emedicine.medscape.com/ article/2006716-overview. Last accessed on 5th May 2020.

5. Govindan R, Page N, Morgensztern D, et al. Changing epidemiology of small-cell lung cancer in the United States over the last 30 years: analysis of the surveillance, epidemiologic, and end results database. J Clin Oncol 2006;24:4539-44.

6. Harris K, Khachaturova I, Azab B, et al. Small cell lung cancer doubling time and its effect on clinical presentation: a concise review. Clin Med Insights Oncol 2012;6:199-203.

7. Available online: https://www.nice.org.uk/guidance/ng122/ chapter/Recommendations\#treatment. Last accessed on 5th May 2020.

8. Faivre-Finn C, Snee M, Ashcroft L, et al. Concurrent once-daily versus twice-daily chemoradiotherapy in patients with limited-stage small-cell lung cancer (CONVERT): an open-label, phase 3, randomised, superiority trial. Lancet Oncol 2017;18:1116-25.

9. Wolf J, Spear P, Yesner R, et al. Nitrogen mustard and the steroid hormones in the treatment of inoperable bronchogenic carcinoma. Am J Med 1960;29:1008-16.

10. Green RA, Humphrey E, Close H, et al. Alkylating agents in bronchogenic carcinoma. Am J Med 1969;46:516-25.

11. Alvarado-Luna G, Morales-Espinosa D. Treatment for small cell lung cancer, where are we now?-a review. Transl Lung Cancer Res 2016;5:26-38.

12. Livingston RB, Bodey GP, Gottlieb JA, et al. Kinetic scheduling of vincristine (NSC-67574) and bleomycin (NSC-125066) in patients with lung cancer and other malignant tumors. Cancer Chemother Rep 1973;57:219-24.

13. Einhorn LH, Fee WH, Farber MO, et al. Improved chemotherapy for small-cell undifferentiated lung cancer. JAMA 1976;235:1225-9.

14. Stinchcombe TE, Gore EM. Limited-stage small cell lung cancer: current chemoradiotherapy treatment paradigms. Oncologist 2010;15:187-95.

15. Bunn PA Jr, Lichter AS, Makuch RW, et al. Chemotherapy 
alone or chemotherapy with chest radiation therapy in limited stage small cell lung cancer. A prospective, randomized trial. Ann Intern Med 1987;106:655-62.

16. Pignon JP, Arriagada R, Ihde DC, et al. A meta-analysis of thoracic radiotherapy for small-cell lung cancer. N Engl J Med 1992;327:1618-24.

17. Schabel FM, Trader MW, Laster WR, et al. cisDichlorodiammineplatinum(II): Combination chemotherapy and cross-resistance studies with tumors of mice. Cancer Treat Rep 1979;63:1459-73.

18. Sierocki JS, Hilaris BS, Hopfan S, et al. cisDichlorodiammineplatinum(II) and VP-16-213: an active induction regimen for small cell carcinoma of the lung. Cancer Treat Rep 1979;63:1593-7.

19. Evans WK, Shepherd FA, Feld R, et al. VP-16 and cisplatin as first-line therapy for small-cell lung cancer. J Clin Oncol 1985;3:1471-7.

20. Turrisi AT 3rd, Kim K, Blum R, et al. Twice-daily compared with once-daily thoracic radiotherapy in limited small-cell lung cancer treated concurrently with cisplatin and etoposide. N Engl J Med 1999;340:265-71.

21. Levy A, Hendriks LEL, Le Péchoux C, et al. Current management of limited-stage SCLC and CONVERT trial impact: Results of the EORTC Lung Cancer Group survey. Lung Cancer 2019;136:145-7.

22. Farrell MJ, Yahya JB, Degnin C, et al. Radiation Dose and Fractionation for Limited-stage Small-cell Lung Cancer: Survey of US Radiation Oncologists on Practice Patterns. Clin Lung Cancer 2019;20:13-9.

23. Available online: https://clinicaltrials.gov/ct2/show/ NCT00632853. Accessed on 15th June 2020

24. Artal-Cortés A, Gomez-Codina J, Gonzales-Larriba JL, et al. Prospective randomised phase III trial of etoposide/ cisplatin versus high-dose epirubicin/cisplatin in small-cell lung cancer. Clin Lung Cancer 2004;6:175-83.

25. Han JY, Cho KH, Lee DH, et al. Phase II study of irinotecan plus cisplatin induction followed by concurrent twice-daily thoracic irradiation with etoposide plus cisplatin chemotherapy for limited-disease small-cell lung cancer. J Clin Oncol 2005;23:3488-94.

26. Kelley MJ, Bogart JA, Hodgson LD, et al. Phase II study of induction cisplatin and irinotecan followed by concurrent carboplatin, etoposide, and thoracic radiotherapy for limited-stage small-cell lung cancer, CALGB 30206. J Thorac Oncol 2013;8:102-8.

27. Klautke G, Fähndrich S, Semrau S, et al. Simultaneous chemoradiotherapy with irinotecan and cisplatin in limited disease small cell lung cancer: a phase I study. Lung Cancer 2006;53:183-8.

28. de Jong WK, de Jonge MJ, van der Leest AH, et al. Irinotecan and cisplatin with concurrent thoracic radiotherapy in a once-every-three-weeks schedule in patients with limited-disease small-cell lung cancer: a phase I study. Lung Cancer 2008;61:123-8.

29. Abdelwahab S, Abdulla H, Azmy A, et al. Integration of irinotecan and cisplatin with early concurrent conventional radiotherapy for limited-disease SCLC (LD-SCLC). Int J Clin Oncol 2009;14:230-6.

30. Jeong HC, Lee SY, Lee SY, et al. Phase II study of irinotecan plus cisplatin with concurrent radiotherapy for the patients with limited-disease small-cell lung cancer. Lung Cancer 2006;53:361-6.

31. Sohn JH, Moon YW, Lee CG, et al. Phase II trial of irinotecan and cisplatin with early concurrent radiotherapy in limited-disease small-cell lung cancer. Cancer 2007;109:1845-950.

32. Kubota K, Hida T, Ishikura S, et al. Etoposide and cisplatin versus irinotecan and cisplatin in patients with limited-stage small-cell lung cancer treated with etoposide and cisplatin plus concurrent accelerated hyperfractionated thoracic radiotherapy (JCOG0202): A randomised phase 3 study. Lancet Oncol 2014;15:106-13.

33. Thomas P, Castelnau O, Paillotin D, et al. Phase II trial of paclitaxel and carboplatin in metastatic small-cell lung cancer: a Groupe Français de Pneumo-Cancérologie study. J Clin Oncol 2001;19:1320-5.

34. Fink TH, Huber RM, Heigener DF, et al. Topotecan/ cisplatin compared with cisplatin/etoposide as first-line treatment for patients with extensive disease small-cell lung cancer: final results of a randomized phase III trial. J Thorac Oncol 2012;7:1432-9.

35. Socinski MA, Smit EF, Lorigan P, et al. Phase III study of pemetrexed plus carboplatin compared with etoposide plus carboplatin in chemotherapy-naive patients with extensive-stage small-cell lung cancer. J Clin Oncol 2009;27:4787-92.

36. Sun Y, Cheng Y, Hao X, et al. Randomized phase III trial of amrubicin/cisplatin versus etoposide/cisplatin as firstline treatment for extensive small-cell lung cancer. BMC Cancer 2016;16:265.

37. Oh IJ, Kim KS, Park CK, et al. Belotecan/cisplatin versus etoposide/cisplatin in previously untreated patients with extensive-stage small cell lung carcinoma: a multi-center randomized phase III trial. BMC Cancer 2016;16:690. 
38. Wolf M, Havemann K, Holle R, et al. Cisplatin/etoposide versus ifosfamide/etoposide combination chemotherapy in small-cell lung cancer: A multicenter German randomized trial. J Clin Oncol 1987;5:1880-9.

39. Sundstrøm S, Bremnes RM, Kaasa S, et al. Cisplatin and etoposide regimen is superior to cyclophosphamide, epirubicin, and vincristine regimen in small-cell lung cancer: Results from a randomized phase III trial with 5 years' follow-up. J Clin Oncol 2002;20:4665-72.

40. Glisson B, Scott C, Komaki R, et al. Cisplatin, ifosfamide, oral etoposide, and concurrent accelerated hyperfractionated thoracic radiation for patients with limited small-cell lung carcinoma: results of radiation therapy oncology group trial 93-12. J Clin Oncol 2000;18:2990-5.

41. Hanna N, Ansari R, Fisher W, et al. Etoposide, ifosfamide and cisplatin (VIP) plus concurrent radiation therapy for previously untreated limited small cell lung cancer (SCLC): a Hoosier Oncology Group (HOG) phase II study. Lung Cancer 2002;35:293-7.

42. Loehrer PJ Sr, Ansari R, Gonin R, et al. Cisplatin plus etoposide with and without ifosfamide in extensive smallcell lung cancer: a Hoosier Oncology Group study. J Clin Oncol 1995;13:2594-9.

43. Baas P, Belderbos JS, Senan S, et al. Concurrent chemotherapy (carboplatin, paclitaxel, etoposide) and involved-field radiotherapy in limited stage small cell lung cancer: a Dutch multicenter phase II study. Br J Cancer 2006;94:625-30.

44. Reck M, von Pawel J, Macha HN, et al. Randomized phase III trial of paclitaxel, etoposide, and carboplatin versus carboplatin, etoposide, and vincristine in patients with small-cell lung cancer. J Natl Cancer Inst 2003;95:1118-27.

45. Mavroudis D, Papadakis E, Veslemes M, et al. A multicenter randomized clinical trial comparing paclitaxelcisplatin-etoposide versus cisplatin-etoposide as first-line treatment in patients with small-cell lung cancer. Ann Oncol 2001;12:463 70.

46. Le QT, McCoy J, Williamson S, et al. Phase I study of tirapazamine plus cisplatin/etoposide and concurrent thoracic radiotherapy in limited-stage small cell lung cancer (S0004): a Southwest Oncology Group study. Clin Cancer Res 2004;10:5418 24.

47. Le QT, Moon J, Redman M, et al. Phase II study of tirapazamine, cisplatin, and etoposide and concurrent thoracic radiotherapy for limited-stage small-cell lung cancer: SWOG 0222. J Clin Oncol 2009;27:3014-19.

48. McClay EF, Bogart J, Herndon JE 2nd, et al. A phase III trial evaluating the combination of cisplatin, etoposide, and radiation therapy with or without tamoxifen in patients with limited-stage small cell lung cancer: Cancer and Leukemia Group B Study (9235). Am J Clin Oncol 2005;28:8190.

49. Lee SM, Woll PJ, Rudd R, et al. Anti-angiogenic therapy using thalidomide combined with chemotherapy in small cell lung cancer: a randomized, double-blind, placebocontrolled trial. J Natl Cancer Inst 2009;101:1049-57.

50. Warde P, Payne D. Does thoracic irradiation improve survival and local control in limited-stage small-cell carcinoma of the lung? A meta-analysis. J Clin Oncol 1992;10:890-5.

51. Takada M, Fukuoka M, Kawahara M, et al. Phase III study of concurrent versus sequential thoracic radiotherapy in combination with cisplatin and etoposide for limited-stage small-cell lung cancer: results of the Japan Clinical Oncology Group Study 9104. J Clin Oncol 2002;20:3054-60.

52. Jeremic B, Shibamoto Y, Acimovic L, et al. Initial versus delayed accelerated hyperfractionated radiation therapy and concurrent chemotherapy in limited small-cell lung cancer: a randomized study. J Clin Oncol 1997;15:893-900.

53. De Ruysscher D, Pijls-Johannesma M, Bentzen SM, et al. Time between the first day of chemotherapy and the last day of chest radiation is the most important predictor of survival in limited-disease small-cell lung cancer. J Clin Oncol 2006;24:1057-63.

54. Fried DB, Morris DE, Poole C, et al. Systematic review evaluating the timing of thoracic radiation therapy in combined modality therapy for limited-stage small-cell lung cancer. J Clin Oncol 2004;22:4837-45.

55. Salama JK, Hodgson L, Pang H, et al. A pooled analysis of limited-stage small-cell lung cancer patients treated with induction chemotherapy followed by concurrent platinumbased chemotherapy and 70 Gy daily radiotherapy: CALGB 30904. J Thorac Oncol 2013;8:1043-9.

56. Johnson DH, Turrisi AT, Chang AY, et al. Alternating chemotherapy and twice-daily thoracic radiotherapy in limited-stage small-cell lung cancer: a pilot study of the Eastern Cooperative Oncology Group. J Clin Oncol 1993;11:879-84.

57. Lebeau B, Urban T, Bréchot JM, et al. A randomized clinical trial comparing concurrent and alternating thoracic irradiation for patients with limited small cell lung carcinoma. "Petites Cellules" Group. Cancer 1999;86:1480-7.

58. Sekine I, Harada H, Yamamoto N, et al. Randomized phase II trial of weekly dose-intensive chemotherapy or 
amrubicin plus cisplatin chemotherapy following induction chemoradiotherapy for limited-disease small cell lung cancer (JCOG1011). Lung Cancer 2017;108:232-7.

59. Pezzi TA, Schwartz DL, Mohamed ASR, et al. Barriers to Combined-Modality Therapy for Limited-Stage Small Cell Lung Cancer. JAMA Oncol 2018;4:e174504.

60. Sallam M, Wong H, Escriu C. Treatment beyond four cycles of first line Platinum and Etoposide chemotherapy in real-life patients with stage IV Small Cell Lung Cancer: a retrospective study of the Merseyside and Cheshire Cancer network. BMC Pulm Med 2019;19:195.

61. Veslemes M, Polyzos A, Latsi P, et al. Optimal duration of chemotherapy in small cell lung cancer: a randomized study of 4 versus 6 cycles of cisplatin-etoposide. J Chemother 1998;10:136-40.

62. Bunn PA Jr, Crowley J, Kelly K, et al. Chemoradiotherapy with or without granulocyte-macrophage colonystimulating factor in the treatment of limited-stage smallcell lung cancer: a prospective phase III randomized study of the Southwest Oncology Group [published correction appears in J Clin Oncol 1995 Nov;13(11):2860]. J Clin Oncol 1995;13:1632-41.

63. Gomes F, Faivre-Finn C, Fernandez-Gutierrez F, et al. Use of G-CSF and prophylactic antibiotics with concurrent chemo-radiotherapy in limited-stage small cell lung cancer: results from the phase III convert trial. Ann Oncol 2017;28:ii61.

64. Smith TJ, Bohlke K, Lyman GH, et al. Recommendations for the Use of WBC Growth Factors: American Society of Clinical Oncology Clinical Practice Guideline Update. J Clin Oncol 2015;33:3199-212.

65. Skarlos DV, Samantas E, Kosmidis P, et al. Randomized comparison of etoposide-cisplatin vs. etoposide-carboplatin and irradiation in small-cell lung cancer. A Hellenic Cooperative Oncology Group study. Ann Oncol 1994;5:601-7.

66. Rossi A, Di Maio M, Chiodini P, et al. Carboplatin- or cisplatin-based chemotherapy in first-line treatment of small-cell lung cancer: the COCIS meta-analysis of individual patient data. J Clin Oncol 2012;30:1692-8.

67. Available online: https://clinicaltrials.gov/ct2/show/ NCT02402920. Last accessed on 16th June 2020.

68. Available online: https://clinicaltrials.gov/ct2/show/ NCT02046733. Last accessed on 16th June 2020.

69. Available online: https://clinicaltrials.gov/ct2/show/ NCT03811002. Last accessed on 16th June 2020.

70. Senan S, Okamoto I, Lee GW, et al. Design and Rationale for a Phase III, Randomized, Placebo-controlled Trial of Durvalumab With or Without Tremelimumab After
Concurrent Chemoradiotherapy for Patients With Limited-stage Small-cell Lung Cancer: The ADRIATIC Study. Clin Lung Cancer 2020;21:e84-e88.

71. Pan Z, Zhang L, Liu C, et al. Cisplatin or carboplatin? Neutrophil to lymphocyte ratio may serve as a useful factor in small cell lung cancer therapy selection. Oncol Lett 2019;18:1513-20.

72. Salem A, Mistry H, Hatton M, et al. Association of Chemoradiotherapy With Outcomes Among Patients With Stage I to II vs Stage III Small Cell Lung Cancer: Secondary Analysis of a Randomized Clinical Trial. JAMA Oncol 2019;5:e185335.

73. Yip D, Harper PG. Predictive and prognostic factors in small cell lung cancer: current status. Lung Cancer 2000;28:173-85.

74. Kawahara M, Fukuoka M, Saijo N, et al. Prognostic factors and prognostic staging system for small cell lung cancer. Jpn J Clin Oncol 1997;27:158-65.

75. Xie D, Marks R, Zhang M, et al. Nomograms Predict Overall Survival for Patients with Small-Cell Lung Cancer Incorporating Pretreatment Peripheral Blood Markers. J Thorac Oncol 2015;10:1213-20.

76. Aktan M, Koc M, Kanyilmaz G, et al. Prognostic value of pre-treatment 18F-FDG-PET uptake in small-cell lung cancer. Ann Nucl Med 2017;31:462-8.

77. Chang H, Lee SJ, Lim J, et al. Prognostic significance of metabolic parameters measured by $18 \mathrm{~F}-\mathrm{FDG}$ PET/CT in limited-stage small-cell lung carcinoma. J Cancer Res Clin Oncol 2019;145:1361-7.

78. Chen J, Jiang R, Garces YI, et al. Prognostic factors for limited-stage small cell lung cancer: a study of 284 patients. Lung Cancer 2010;67:221-6.

79. Sas-Korczynska B, Sokolowski A, Korzeniowski S. The influence of time of radio-chemotherapy and other therapeutic factors on treatment results in patients with limited disease small cell lung cancer. Lung Cancer 2013;79:14-9.

80. Wen Q, Meng X, Xie P, et al. Evaluation of factors associated with platinum-sensitivity status and survival in limited-stage small cell lung cancer patients treated with chemoradiotherapy. Oncotarget 2017;8:81405-18.

81. Ding C, Li J, Wang S, et al. Prognostic factors for patients with limited-stage small-cell lung cancer without receiving prophylactic cranial irradiation, Radiation Medicine and Protection, Available online: https://doi.org/10.1016/ j.radmp.2020.05.002

82. Tay RY, Fernández-Gutiérrez F, Foy V, et al. Prognostic value of circulating tumour cells in limited-stage small- 
cell lung cancer: analysis of the concurrent once-daily versus twice-daily radiotherapy (CONVERT) randomised controlled trial. Ann Oncol 2019;30:1114-20.

83. Rudin CM, Poirier JT, Byers LA, et al. Molecular subtypes of small cell lung cancer: a synthesis of human and mouse model data [published correction appears in Nat Rev Cancer. 2019 Jun 7]. Nat Rev Cancer 2019;19:289-97.

84. Arnold AM, Seymour L, Smylie M, et al. Phase II study of vandetanib or placebo in small-cell lung cancer patients after complete or partial response to induction chemotherapy with or without radiation therapy: National Cancer Institute of Canada Clinical Trials Group Study BR.20. J Clin Oncol 2007;25:4278-84.

85. Giaccone G, Debruyne C, Felip E, et al. Phase III study of adjuvant vaccination with Bec2/bacille CalmetteGuerin in responding patients with limited-disease smallcell lung cancer (European Organisation for Research and Treatment of Cancer 08971-08971B; Silva Study). J Clin Oncol 2005;23:6854-64.

86. Kelly K, Crowley JJ, Bunn PA Jr, et al. Role of recombinant interferon alfa-2a maintenance in patients with limited-stage small-cell lung cancer responding to concurrent chemoradiation: a Southwest Oncology Group study. J Clin Oncol 1995;13:2924-30.

87. van Zandwijk N, Groen HJ, Postmus PE, et al. Role of recombinant interferon-gamma maintenance in responding patients with small cell lung cancer. A randomised phase III study of the EORTC Lung Cancer Cooperative Group. Eur J Cancer 1997;33:1759-66.

88. Jett JR, Maksymiuk AW, Su JQ, et al. Phase III trial of recombinant interferon gamma in complete responders with small-cell lung cancer. J Clin Oncol 1994;12:2321-6.

89. Rossi A, Garassino MC, Cinquini M, et al. Maintenance or consolidation therapy in small-cell lung cancer: a systematic review and meta-analysis. Lung Cancer 2010;70:119-28.

90. Spigel DR, Hainsworth JD, Yardley DA, et al. Tracheoesophageal fistula formation in patients with lung cancer treated with chemoradiation and bevacizumab. J Clin Oncol 2010;28:43-8.

91. Paz-Ares L, Dvorkin M, Chen Y, et al. Durvalumab plus platinum-etoposide versus platinum-etoposide in firstline treatment of extensive-stage small-cell lung cancer (CASPIAN): a randomised, controlled, open-label, phase 3 trial. Lancet 2019;394:1929-39.

92. Rudin CM, Awad MM, Navarro A, et al. Pembrolizumab or Placebo Plus Etoposide and Platinum as First-Line Therapy for Extensive-Stage Small-Cell Lung Cancer: Randomized, Double-Blind, Phase III KEYNOTE-604 Study. J Clin Oncol 2020;2369-79.

93. Antonia SJ, Villegas A, Daniel D, et al. Overall Survival with Durvalumab after Chemoradiotherapy in Stage III NSCLC. N Engl J Med 2018;379:2342-50.

94. Siu LL, Shepherd FA, Murray N, et al. Influence of age on the treatment of limited-stage small-cell lung cancer. J Clin Oncol 1996;14:821-8.

95. Safont MJ, Artal-Cortes A, Sirera R, et al. Retrospective study of efficacy and toxicity on patients older than 70 years within a randomized clinical trial of two cisplatinbased combinations in patients with small-cell lung cancer. Lung Cancer 2009;63:83-7.

96. Corso CD, Rutter CE, Park HS, et al. Role of Chemoradiotherapy in Elderly Patients With Limited-Stage Small-Cell Lung Cancer. J Clin Oncol 2015;33:4240-6.

97. Yuen AR, Zou G, Turrisi AT, et al. Similar outcome of elderly patients in intergroup trial 0096: Cisplatin, etoposide, and thoracic radiotherapy administered once or twice daily in limited stage small cell lung carcinoma. Cancer 2000;89:1953-60.

98. Schild SE, Stella PJ, Brooks BJ, et al. Results of combinedmodality therapy for limited-stage small cell lung carcinoma in the elderly. Cancer 2005;103:2349-54.

99. Christodoulou M, Blackhall F, Mistry H, et al. Compliance and Outcome of Elderly Patients Treated in the Concurrent Once-Daily Versus Twice-Daily Radiotherapy (CONVERT) Trial. J Thorac Oncol 2019;14:63-71.

100.Ludbrook JJ, Truong PT, MacNeil MV, et al. Do age and comorbidity impact treatment allocation and outcomes in limited stage small-cell lung cancer? a communitybased population analysis. Int J Radiat Oncol Biol Phys 2003;55:1321-30.

101.Halvorsen TO, Sundstrøm S, Fløtten Ø, et al. Comorbidity and outcomes of concurrent chemo- and radiotherapy in limited disease small cell lung cancer. Acta Oncol 2016;5 5:1349-54.

Cite this article as: Noronha V, Sekhar A, Patil VM, Menon N, Joshi A, Kapoor A, Prabhash K. Systemic therapy for limited stage small cell lung carcinoma. J Thorac Dis 2020;12(10):62756290. doi: 10.21037/jtd-2019-sclc-11 